\title{
COMPARISON OF CFD SIMULATION OF HOT AND COLD FLUID MIXING IN T-PIPE BY PLACING NOZZLE AT DIFFERENT PLACES
}

\author{
K.Venkateswara Rao ${ }^{1}$, V.V.RamaKrishna ${ }^{2}$, V.Subrahmanyam ${ }^{3}$ \\ ${ }^{l}$ M.Tech Scholar, Department of Mechanical Engineering, Kakinada Institute of Technology and Science, Divili, \\ Andhra Pradesh, India \\ ${ }^{2}$ Assistant Professor, Department of Mechanical Engineering, Kakinada Institute of Technology and Science, Divili, \\ Andhra Pradesh, India \\ ${ }^{3}$ Ph.D Scholar, Department of Mechanical Engineering, J.N.T.U. Kakinada, Andhra Pradesh, India
}

\begin{abstract}
The project deals with the computational fluid dynamics analysis of mixed flow of hot and cold water in T-pipes and it is mainly concentrated on analytical approach to the areas where Pipes (used for flow) are mostly susceptible to damage. The simulation is done on T-pipe by placing the nozzle at three different places, to know the pressure, temperature and velocity contours throughout the flow and comparison was made. These T-pipes are mostly used in nuclear reactor cooling system to reduce the heat in the nuclear reactors by mixing hot and cold water, where the mixing will takes place efficiently. And mixed flow at the outlet will take heat from the inlet also due to convective heat transfer loss; the temperature at the boundaries of the T-pipe will be reduced. The $2 D$ model of the pipe is made by GAMBIT and analysis is to be carried out by using K-Epsilon in FLUENT software. The models are first generated using the data and then various velocity, temperature and pressure contours are to be drawn and graphed to analyze the flow through the pipe.
\end{abstract}

Keywords: Gambit, Fluent, K-Epsilon model.

\section{INTRODUCTION}

Pipe networks are mainly used for transportation of fluids from one place to another. In addition to pipes, the network also consists of elbow, T-junctions, bends, contractions, expansions, valves, meters, pumps, turbines and many other components. All these components cause loss in pressure due to change in momentum of the flow caused due to friction and pipe components. This means conversion of flow energy in to heat due to friction or energy lost due to turbulence.

Flow analysis is very important in nuclear power plant cooling systems to know how the variations are taking place with respect to the cross section. These $\mathrm{T}$ - pipes are used in nuclear power plant cooling systems to reduce the heat in the nuclear reactors by mixing hot water with cold water in the $\mathrm{T}$ - pipes where the mixing will takes place efficiently and mixed flow at the outlet take the heat from the inlet and releases out at temperature to atmospheric temperature. Turbulent mixing of fluid of different temperature in $\mathrm{T}$ junction geometries became of significant importance in the field of nuclear reactor safety, since it can lead to highly transient temperature fluctuations at the adjacent pipe walls, cyclic thermal stresses in the pipe walls and consequently to thermal fatigue and failure of the pipe line. Mixing fluid of different temperature in $\mathrm{T}$-junction geometries became of significant importance in the field of nuclear reactor safety.

\section{PROCEDURE AND GEOMETRY}

The current study used FLUENT software, to solve the balance equation using control volume approach. These equations are solved by converting the complex partial differential equations into simple algebraic equations. In the GAMBIT software, a fine meshing is done by using successive ratio and later given the boundary conditions for the geometry and for the media.

The geometry was done in the GAMBIT with measurements; pipe diameter is $50 \mathrm{~mm}$, radius of the pipe $25 \mathrm{~mm}$ and length of the pipe $500 \mathrm{~mm}$. Defining required boundaries like inlet, outlet and wall of the geometry and mesh under tetrahedron. Defining the boundary conditions for the water. The velocity at inlet of the cold fluid is $4 \mathrm{~m} / \mathrm{sec}$ and at outlet is $2 \mathrm{~m} / \mathrm{sec}$ and the gravitational acceleration of $9.81 \mathrm{~m} / \mathrm{s} 2$ in downward flow direction was used. 


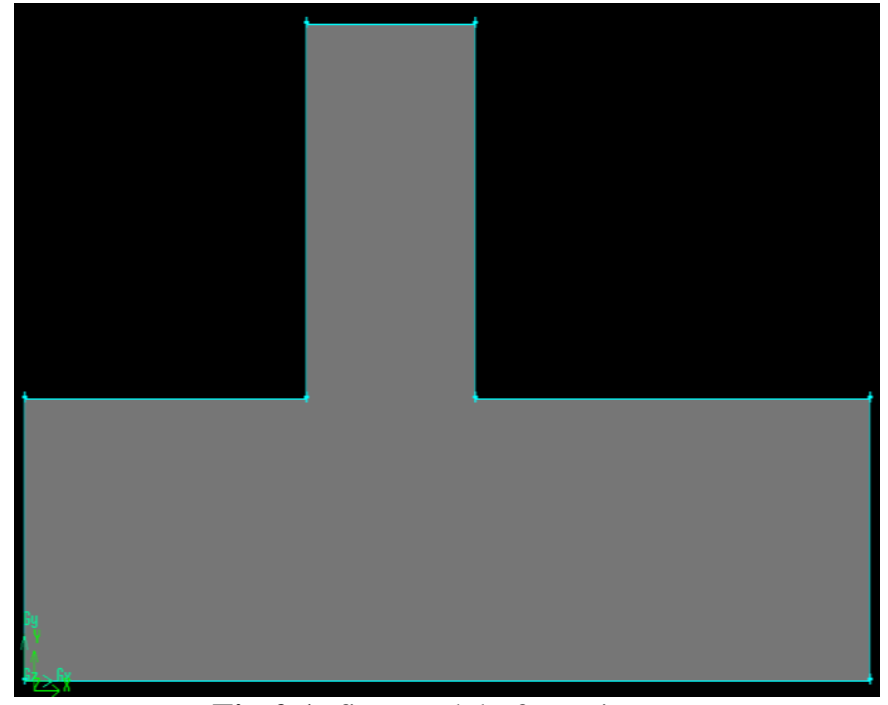

Fig-2.1: first model of tee pipe.

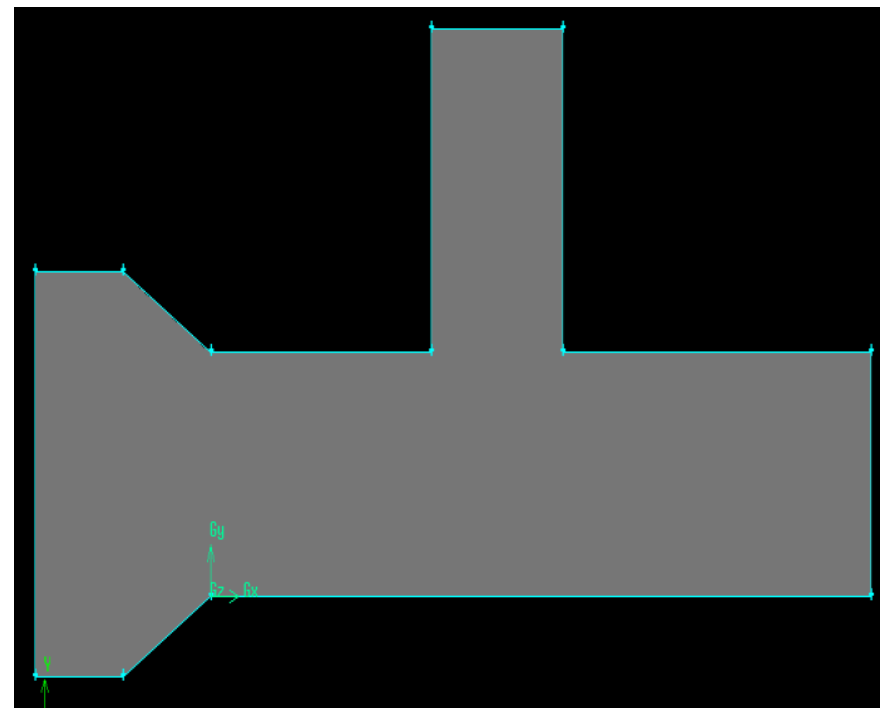

Fig-2.2: second model of tee pipe.

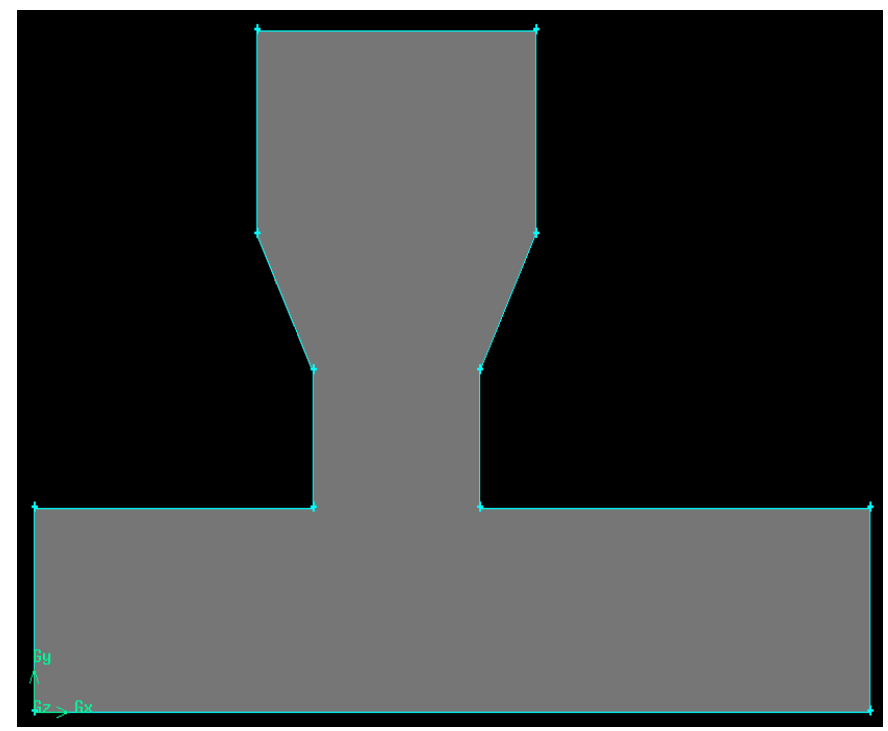

Fig-2.3: third model of tee pipe.

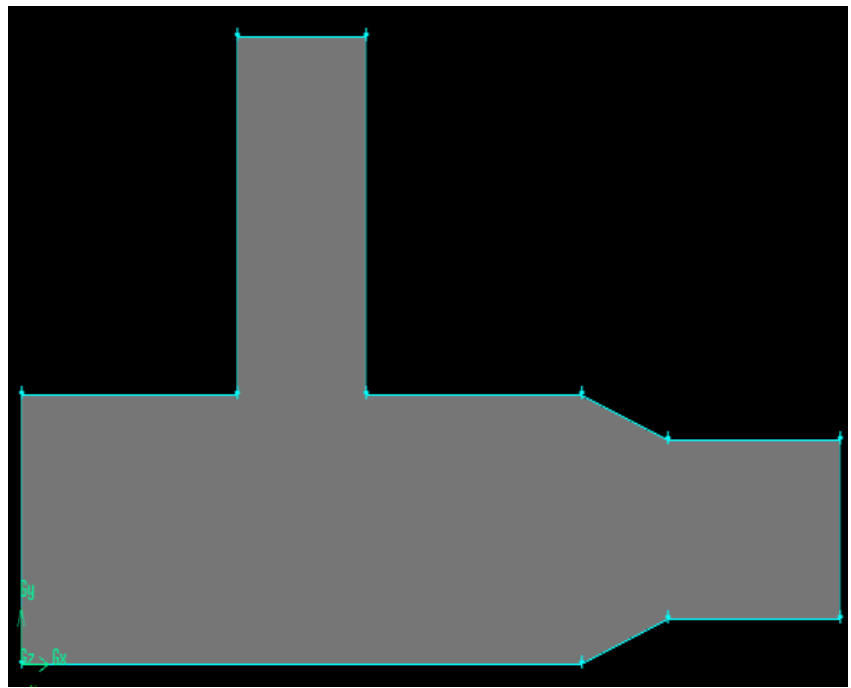

Fig-2.4: forth model of tee pipe.

\section{SOLUTION STRATEGY}

The simulation is done in the FLUENT based upon the governing equations. The steps followed in the fluent are define Model, define Material, define cell zone, boundary condition, solve, iterate, and analyze results. The convergent of the solution is shown in below fig 3.1.

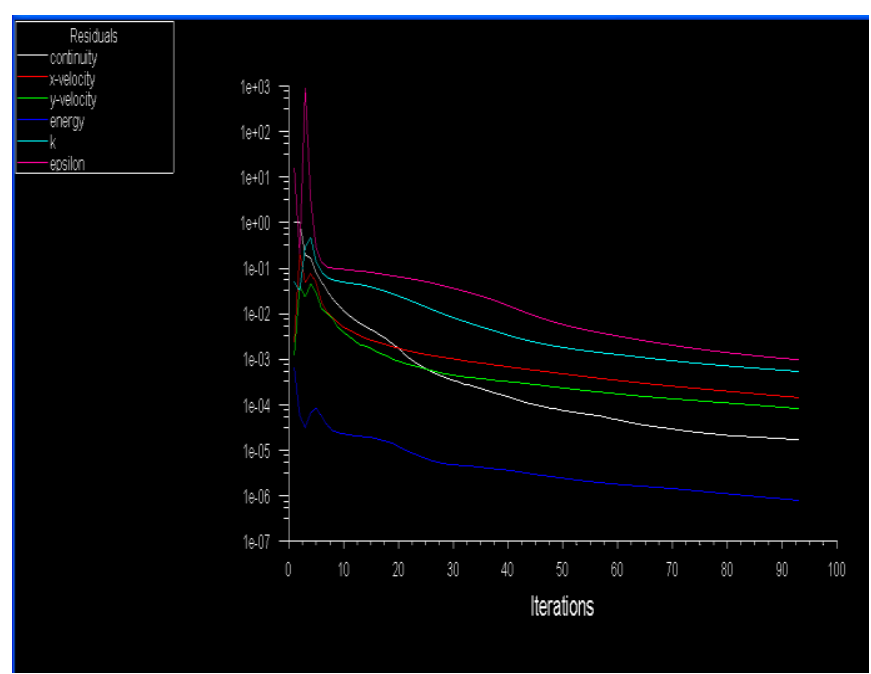

Fig-3.1: iterations of solution.

\subsection{Continuity Equation}

Continuity Equation also called conservation of mass. The overall mass balance is

$$
\text { Input }- \text { output }=\text { accumulation }
$$

Assuming that there is no storage the Mass input = mass output.

However, as long as the flow is steady (time-invariant), within this tube, since, mass cannot be created or destroyed then the above equation will be

$$
\mathrm{m}_{1}=\mathrm{m}_{1}
$$




$$
\begin{aligned}
& \frac{\mathrm{dm}_{1}}{\mathrm{dt}}=\frac{\mathrm{dm_{1 }}}{\mathrm{dt}} \\
& \rho \mathrm{A}_{1} \mathrm{u}_{1}=\rho \mathrm{A}_{2} \mathrm{u}_{2} \\
& \mathrm{~A}_{1} \mathrm{v}_{1}=\mathrm{A}_{2} \mathrm{v}_{2}
\end{aligned}
$$

\subsection{Momentum Equation and Bernoulli Equation}

It is also called equation of motion .According to Newton's 2nd law (the time rate of change of momentum of the fluid particles within this stream tube slice must equal to the forces acting on it).

$$
\mathrm{F}=\text { mass } * \text { acceleration }
$$

Consider a small element of the flowing fluid as shown below, Let

dA : cross-sectional area of the fluid element,

$\mathrm{dL} \quad$ : Length of the fluid element,

$\mathrm{dW} \quad$ : Weight of the fluid element,

$\mathrm{u} \quad$ : Velocity of the fluid element,

$\mathrm{P} \quad$ : Pressure of the fluid element.

Assuming that the fluid is steady, non-viscous (the frictional losses are zero) and incompressible (the density of fluid is constant).

The forces on the cylindrical fluid element are,

Pressure force acting on the direction of flow (PdA).

Pressure force acting on the opposite direction of flow $[(\mathrm{P}+\mathrm{dP}) \mathrm{dA}]$.

A component of gravity force acting on the opposite direction of flow $(\mathrm{dW} \sin \theta)$.

Hence, Total force $=$ gravity force + pressure force

The pressure force in the direction of low

$$
F p=P d A-(P+d P) d A=-d P d A
$$

The gravity force in the direction of flow

$$
\begin{aligned}
\mathrm{Fg} & =-\mathrm{dW} \sin \theta\{\mathrm{W}=\mathrm{m} \mathrm{g}=\rho \mathrm{dAdL} \mathrm{g}\} \\
& =-\rho \mathrm{gdAdL} \sin \theta\{\sin \theta=\mathrm{dz} / \mathrm{dL}\} \\
& =-\rho \mathrm{gdAdz} .
\end{aligned}
$$

The net force in the direction of flow

$$
\begin{aligned}
\mathrm{F} & =\mathrm{m} \text { a }\{\mathrm{m}=\rho \mathrm{dA} \mathrm{dL} . \\
& =\rho \mathrm{dA} d \mathrm{dL} . \\
& =\rho \mathrm{dA} \mathrm{u} d u .
\end{aligned}
$$

We have

$\rho \mathrm{dA} \mathrm{u} \mathrm{du}=-\mathrm{dPdA}-\rho \mathrm{gdAdz}\{\div \rho \mathrm{dA}\}$

$\mathrm{dP} / \rho+\mathrm{udu}+\mathrm{dz} \mathrm{g}=0$--------- Euler's equation of motion.
Bernoulli's equation could be obtain by integration the Euler's equation.

$\int \mathrm{dP} / \rho+\int \mathrm{udu}+\int \mathrm{dz} \mathrm{g}=$ constant.

$\mathrm{P} / \rho+\mathrm{u} 2 / 2+\mathrm{z} \mathrm{g}=$ constant.

$\Delta \mathrm{P} / \rho+\Delta \mathrm{u} 2 / 2+\Delta \mathrm{z} g=0$-- Bernoulli's equation.

\section{RESULTS}

\subsection{Results of First Model}

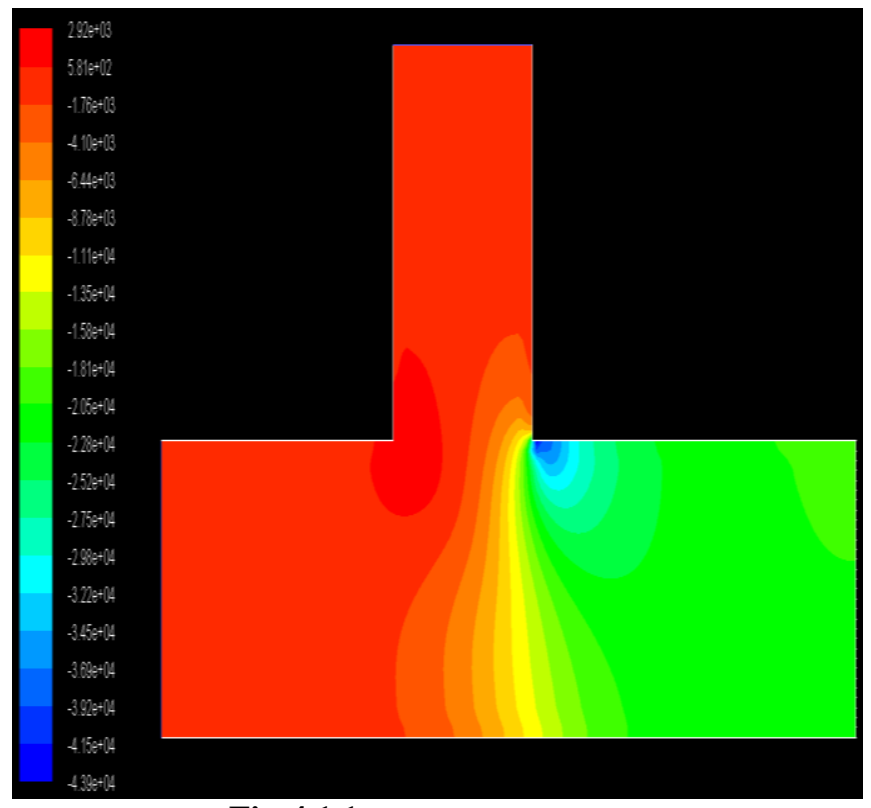

Fig-4.1.1: pressure contours.

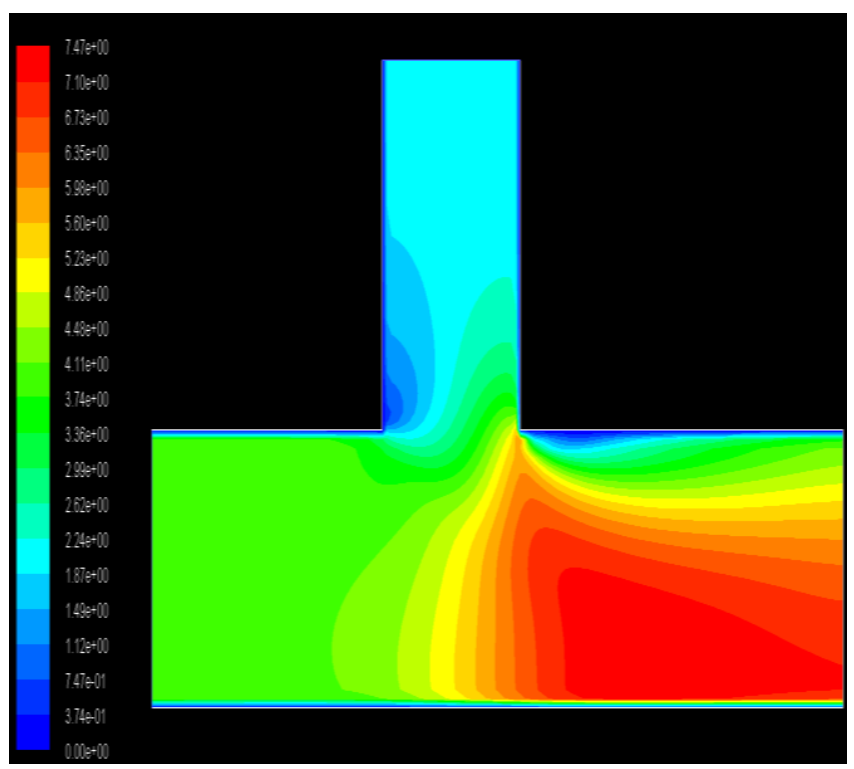

Fig-4.1.2: velocity contours. 


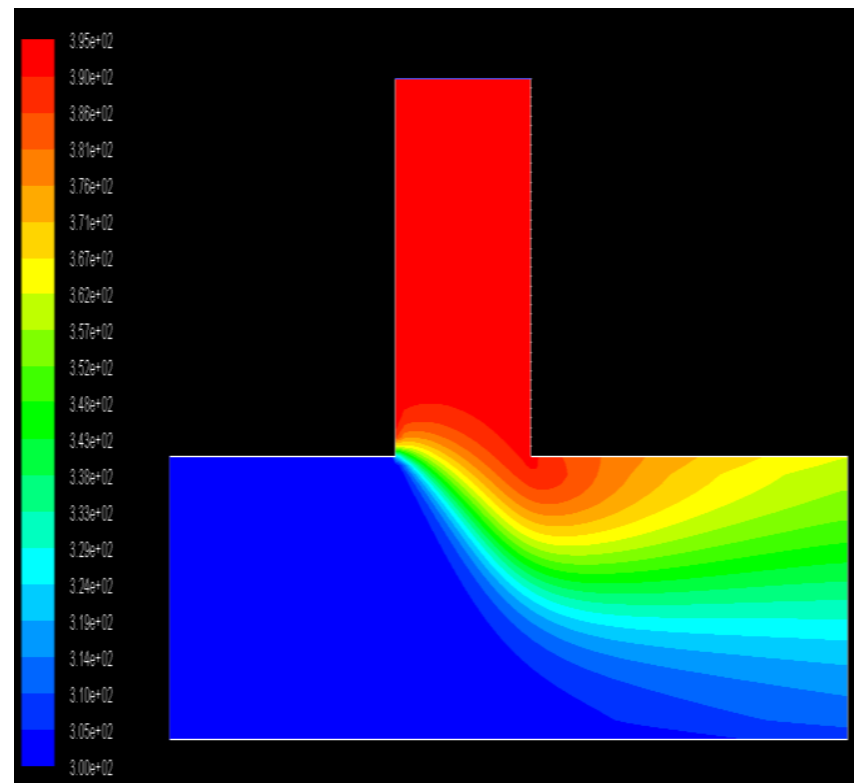

Fig-4.1.3: temperature contours.

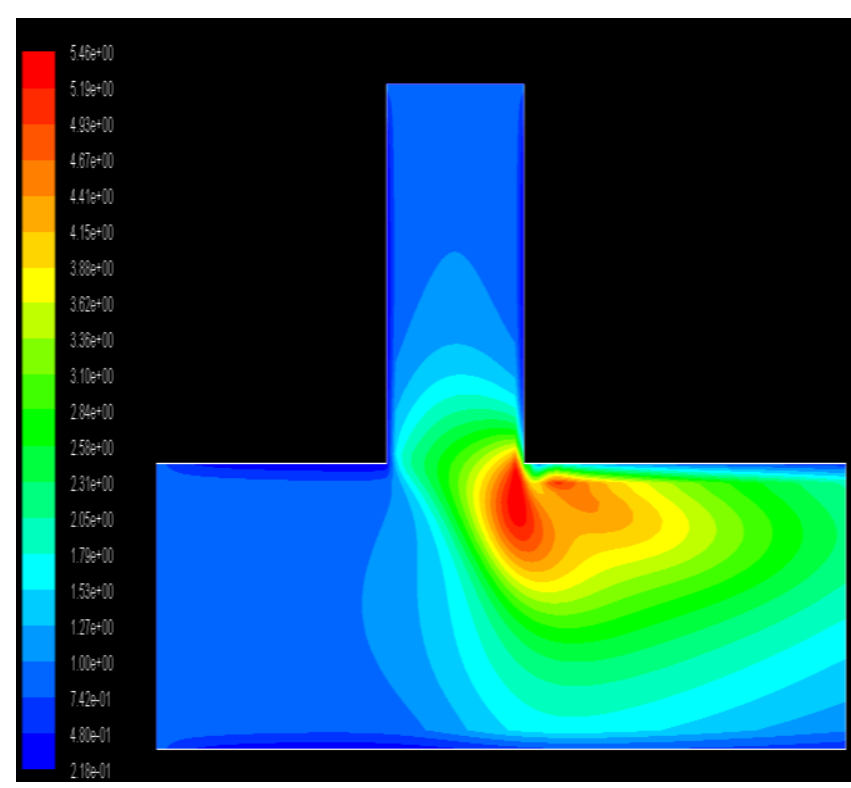

Fig-4.1.4: turbulence contours.

Table-4.1.1: results of flow analysis.

\begin{tabular}{|l|l|l|l|}
\hline S.No & Parameters & Min. & Max. \\
\hline 1 & Pressure $($ Pascal $)$ & -43875.04 & 2921.139 \\
\hline 2 & Velocity $(\mathrm{m} / \mathrm{s})$ & 0 & 7.472435 \\
\hline 3 & Temperature $(\mathrm{K})$ & 300 & 395 \\
\hline 4 & Turbulent $\left(\mathrm{m}^{2} / \mathrm{s}^{2}\right)$ & 0.218194 & 5.456457 \\
\hline
\end{tabular}

Table-4.1.2: results of mass flow rate.

\begin{tabular}{|l|l|}
\hline Mass Flow Rate & $\mathbf{( k g / s )}$ \\
\hline Interior & -21023.578 \\
\hline Inlet_C & 119.78401 \\
\hline Inlet_H & 59.892004 \\
\hline Outlet & -179.67601 \\
\hline Wall & 0 \\
\hline
\end{tabular}

\subsection{Results of Second Model}

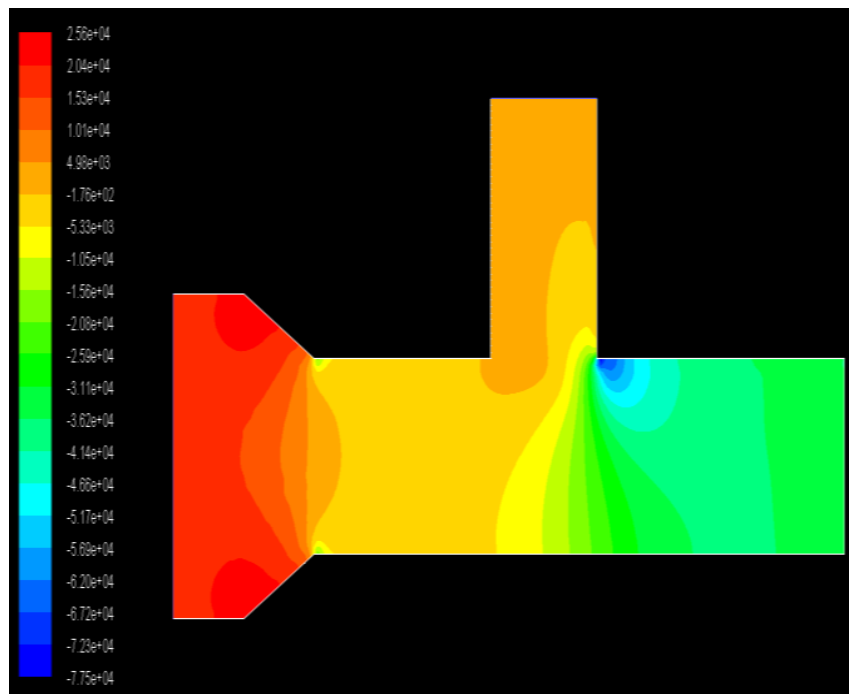

Fig-4.2.1: pressure contours.

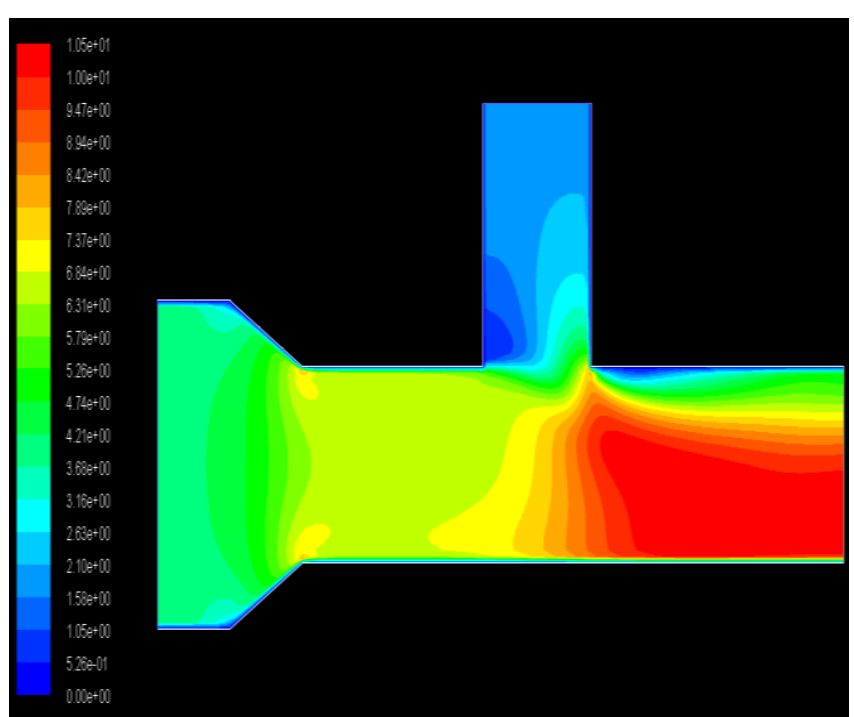

Fig-4.2.2: velocity contours.

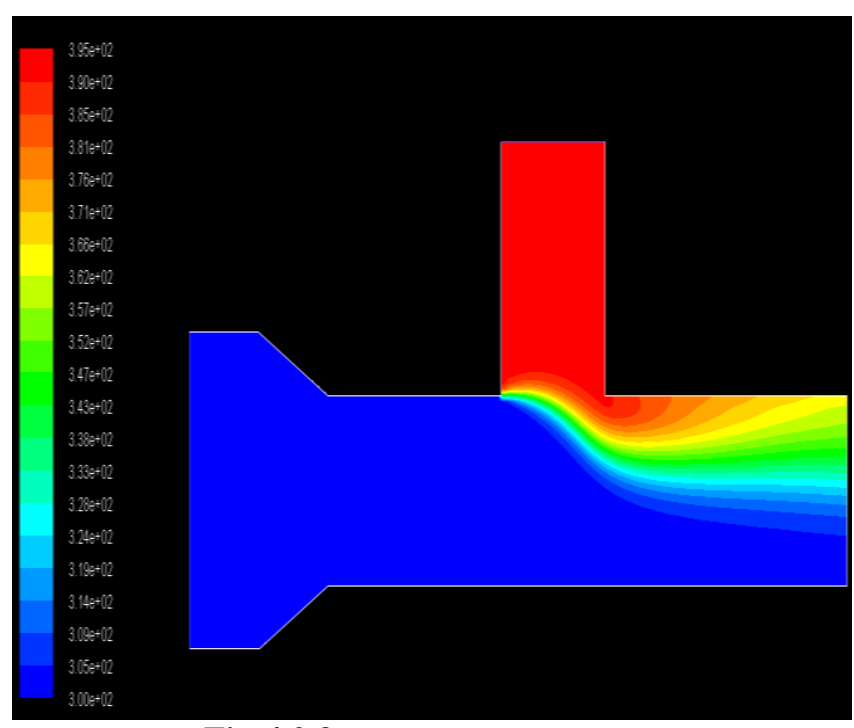

Fig-4.2.3: temperature contours. 


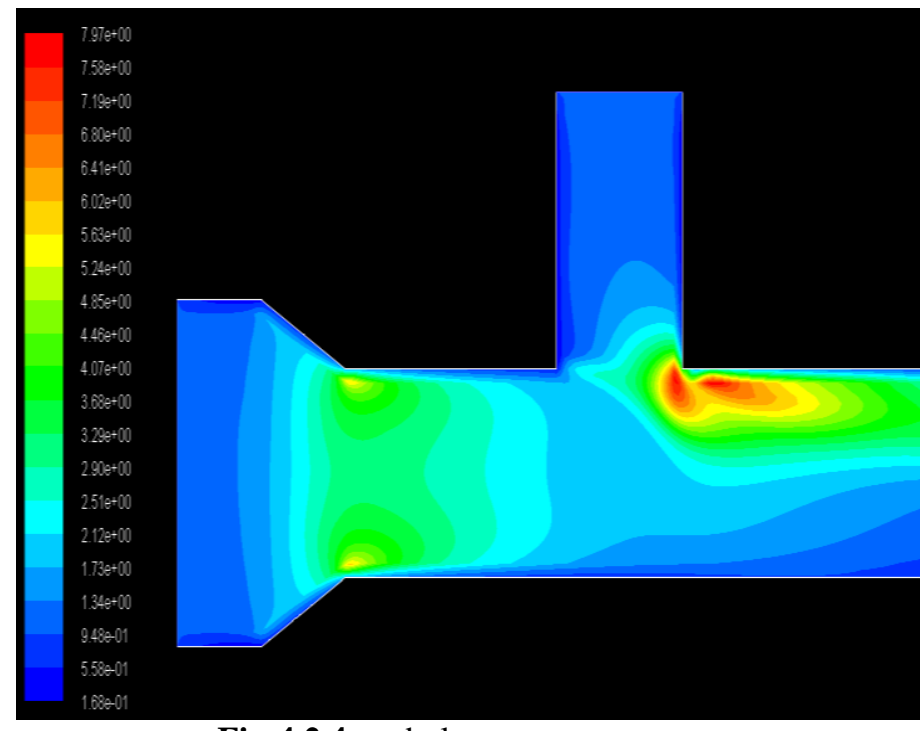

Fig-4.2.4: turbulence contours.

Table-4.2.1: results of flow analysis.

\begin{tabular}{|l|l|l|l|}
\hline S.No & Parameters & Min. & Max. \\
\hline 1 & Pressure $($ Pascal $)$ & -77467.77 & 25588.5 \\
\hline 2 & Velocity $(\mathrm{m} / \mathrm{s})$ & 0 & 10.52352 \\
\hline 3 & Temperature $(\mathrm{K})$ & 300 & 395 \\
\hline 4 & Turbulent $\left(\mathrm{m}^{2} / \mathrm{s}^{2}\right)$ & 0.1677168 & 7.973526 \\
\hline
\end{tabular}

Table-4.2.2: results of mass flow rate.

\begin{tabular}{|l|l|}
\hline Mass Flow Rate & $\mathbf{( k g / s )}$ \\
\hline Interior & -4658.3701 \\
\hline Inlet_C & 199.64001 \\
\hline Inlet_H & 59.892004 \\
\hline Outlet & -259.53202 \\
\hline Wall & 0 \\
\hline
\end{tabular}

\subsection{Results of Third Model}

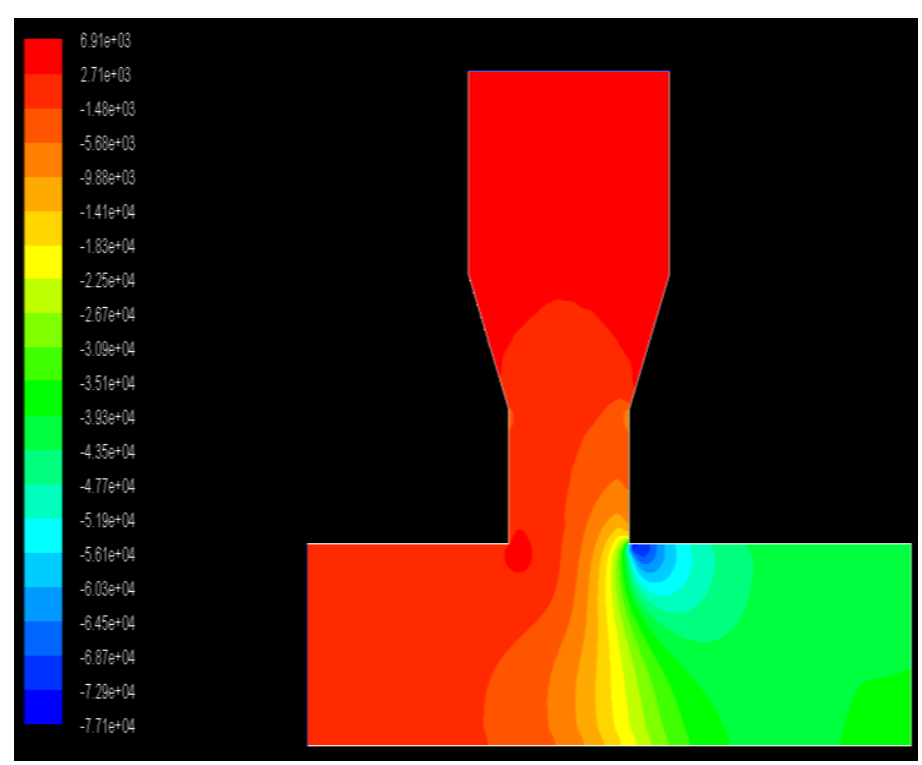

Fig-4.3.1: pressure contours.

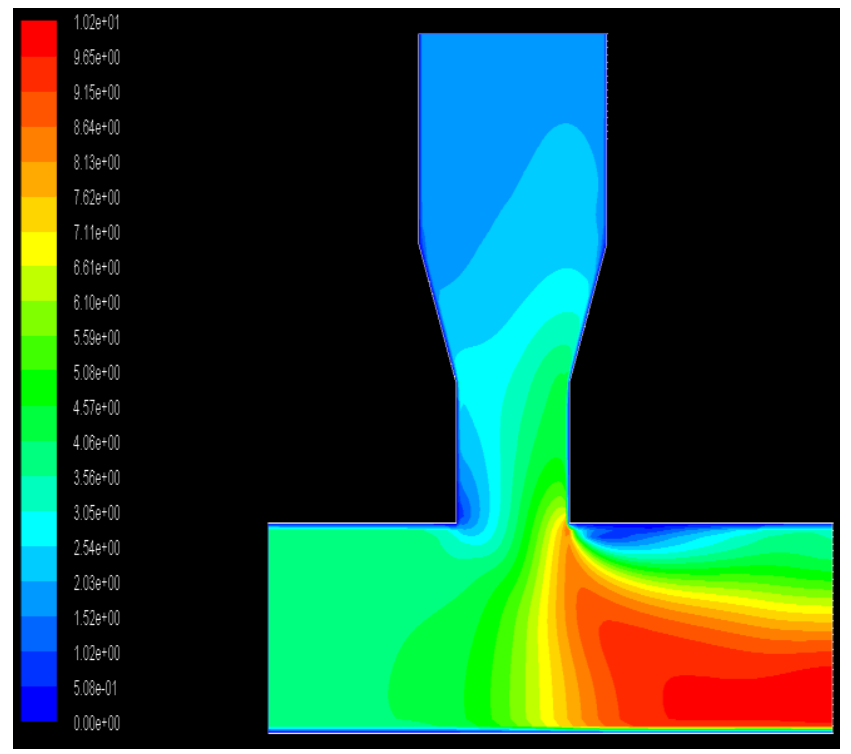

Fig-4.3.2: velocity contours.

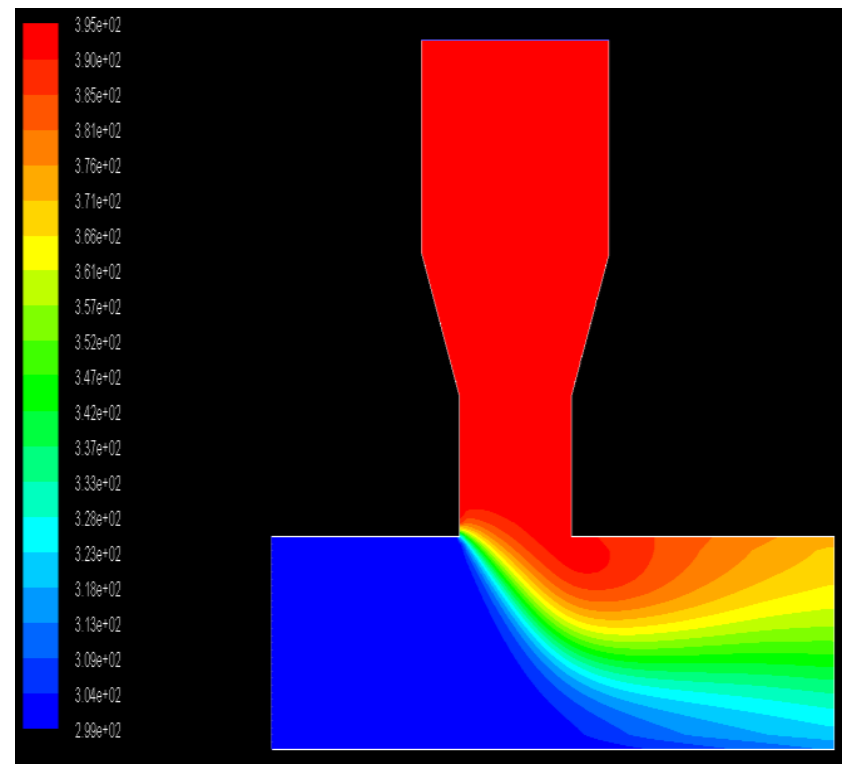

Fig-4.3.3: temperature contours.

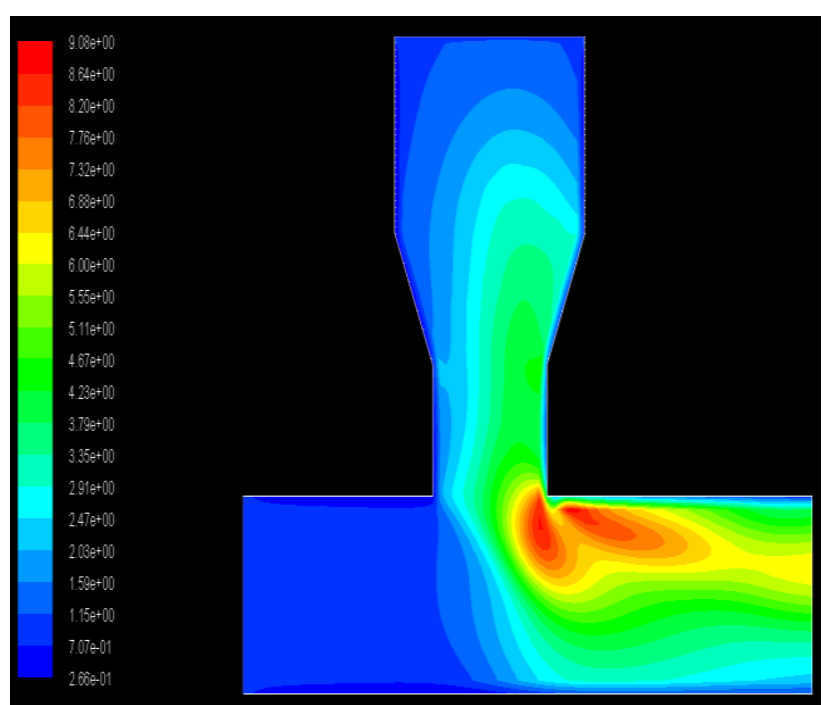

Fig-4.3.4: turbulence contours. 
Table-4.3.1: results of flow analysis.

\begin{tabular}{|l|l|l|l|}
\hline S.No & Parameters & Min. & Max. \\
\hline 1 & Pressure $($ Pascal $)$ & -77065.7 & 6913.483 \\
\hline 2 & Velocity $(\mathrm{m} / \mathrm{s})$ & 0 & 10.16165 \\
\hline 3 & Temperature $(\mathrm{K})$ & 300 & 395 \\
\hline 4 & Turbulent $\left(\mathrm{m}^{2} / \mathrm{s}^{2}\right)$ & 0.2659736 & 9.080444 \\
\hline
\end{tabular}

Table-4.3.2: results of mass flow rate.

\begin{tabular}{|l|l|}
\hline Mass Flow Rate & $\mathbf{( k g / s )}$ \\
\hline Interior & -4485.8018 \\
\hline Inlet_C & 119.78401 \\
\hline Inlet_H & 99.820006 \\
\hline Outlet & -219.60401 \\
\hline Wall & 0 \\
\hline
\end{tabular}

\subsection{Results of Forth Model}

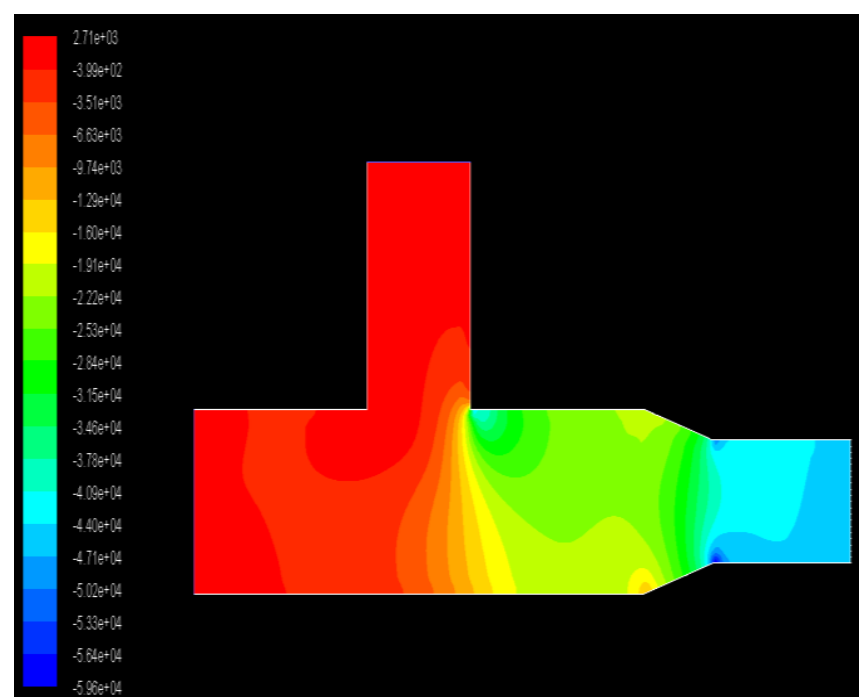

Fig-4.4.1: pressure contours.

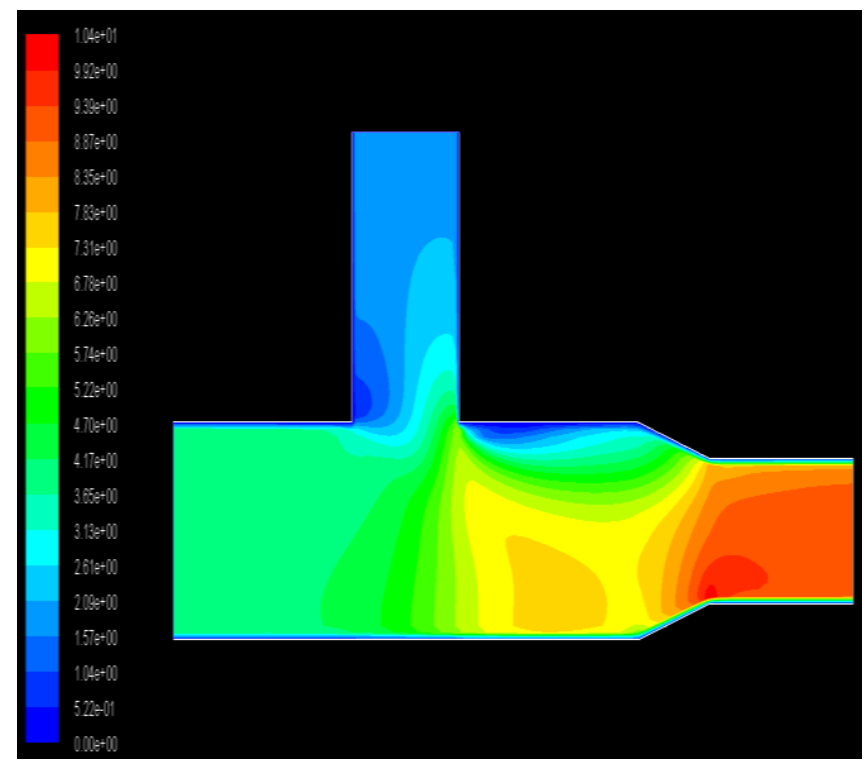

Fig-4.4.2: velocity contours.

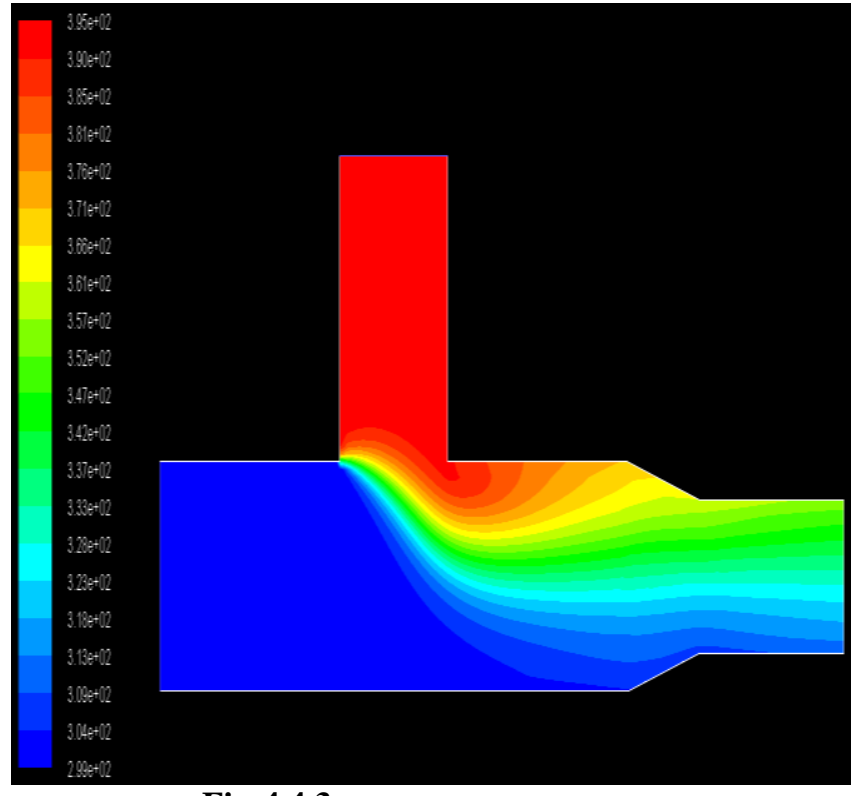

Fig-4.4.3: temperature contours.

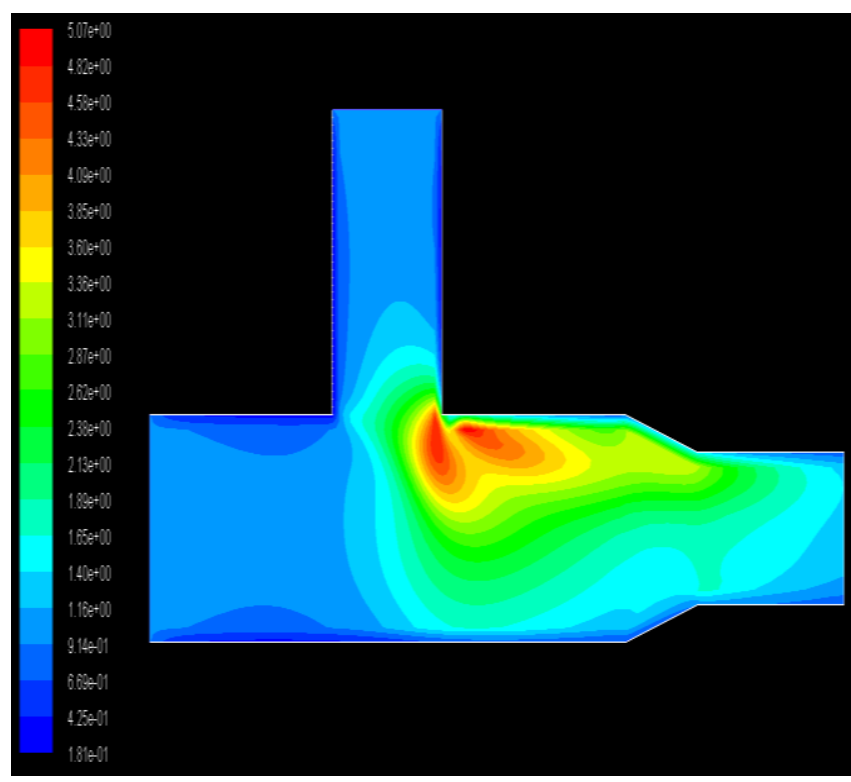

Fig-4.4.4: turbulence contours.

Table-4.4.1: results of flow analysis.

\begin{tabular}{|l|l|l|l|}
\hline S.No & Parameters & Min. & Max. \\
\hline 1 & Pressure $($ Pascal $)$ & -59552.35 & 2714.012 \\
\hline 2 & Velocity $(\mathrm{m} / \mathrm{s})$ & 0 & 10.43727 \\
\hline 3 & Temperature $(\mathrm{K})$ & 300 & 395 \\
\hline 4 & Turbulent $\left(\mathrm{m}^{2} / \mathrm{s}^{2}\right)$ & 0.1806357 & 5.066483 \\
\hline
\end{tabular}

Table-4.4.2: results of mass flow rate.

\begin{tabular}{|l|l|}
\hline Mass Flow Rate & $\mathbf{( k g / s )}$ \\
\hline Interior & -3245.6271 \\
\hline Inlet_C & 119.78401 \\
\hline Inlet_H & 59.892004 \\
\hline Outlet & -179.67601 \\
\hline Wall & 0 \\
\hline
\end{tabular}




\section{CONCLUSIONS}

From the above analysis it is found out that flow will change greatly in t-pipe due to different cross section and also because of hot and cold water mixing process. Temperature, pressure and velocity variations occur at the outlet from the cold and hot water inlets. Hot water will possess a high average kinetic energy and cold water will possess low average kinetic energy, the mixture will have an average kinetic energy of an intermediate value. Initially hot water and cold water mixes up to some extent as the cross section goes on increasing mixing hot and cold water takes place completely then the temperature of the mixed flow reduces.

As the hot water and cold water enters at different velocities of mixed flow will be increased as pressure decreases. Pressure for mixed flow at the outlet will be reduced because of the cross section variation at the joining point of hot and cold water and also high velocities will cause more pressure drop. Turbulence is created at the inter section point of the T-pipe because the cross section at that point has changed suddenly and also the velocity at that point has increased suddenly due to the mixing of hot and cold water at that point.

\section{REFERENCES}

[1]. Large eddy simulation of hot and cold fluids mixing in a T-junction for predicting thermal fluctuations, Wie-yu Zhu, Tao Lu, Pie-xue Jiang Zhi-jun Guo Kuishing Wang, November 2009, volume 30, Issue 11, pp 1379-1392.

[2]. Simulation of turbulent and thermal mixing in Tjunctions using urans and scale-resolving turbulence models in Ansys cfx, Th. Frank, M.Adlakha, C. Lifante, H.M. Prasser, F.Menter, ANSYS Germany GmbH, Staudenfeldweg 12, D-83624 Otterfing, Germany ETH Zürich, Dept. Energy Technology, Zürich, Switzerland.

[3]. A coupled CFD-FEM strategy to predict thermal fatigue in mixing tees of nuclear reactors, M.H.C. Hannink, A.K. Kuczaj, F.J. Blom, J.M. Church and E.M.J. Komen.

[4]. Thermal mixing of two miscible fluids in a T-shaped micro channel, Bin Xu, Teck Neng Wong, Nam-Trung Nguyen, Zhizhao Che, John Chee Kiong Chai, Dec 2010; 4(4): 044102. Published online Oct 1, 2010.

[5]. Assessment of thermal fatigue in mixing tee by fsi analysis, myung jo jhung, Research Management Department, Korea Institute of Nuclear Safety 62 Gwahakro, Yuseong-gu, Daejeon, 305-338, Korea, Received April 12, 2012 , Accepted for Publication June 27, 2012.

[6]. Large-eddy simulation of fluid flow and heat transfer in a mixing tee junction, Tao Lu, Yongwei Wang, Kuisheng Wang, Chinese Journal of Mechanical Engineering November 2012, Volume 25, Issue 6, pp 1144-1150.

[7]. A coupled CFD-FEM strategy to predict thermal fatigue in mixing fluids of nuclear reactors, M.H.C. Hannink, A.K. Kuczaj, F.J. Blom, J.M. Church and E.M.J. Komen.

[8]. ANSYS, Inc., 2010, ANSYS CFX-Solver Theory Guide and ANSYS CFX-Solver Manager User's Guide, Canonsburg, PA.

[9]. ANSYS, Inc., 2010, Theory Reference for ANSYS and ANSYS Workbench Release 13.0, Canonsburg, PA.
[10]. Bannantine, J.A., Comer, J.J., Hand rock, J.L., 1989, Fundamentals of Metal Fatigue Analysis, Prentice Hall, New Jersey.

\section{BIOGRAPHIES}

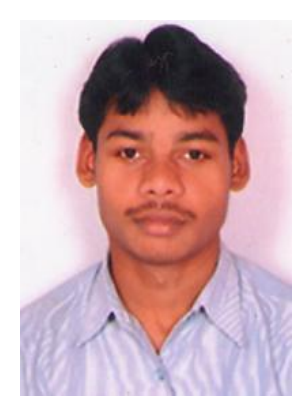

1. K.Venkateswara Rao completed schooling from TWAB High school, West Godavari district with $84 \%$ marks. Completed B.Tech degree from Madhira institute of technology and Sciences with $71 \%$. Now pursuing M.Tech from Kakinada Institute of Technology and Science, Tirupathi(V), Divili, East Godavari Dist., A.P., India

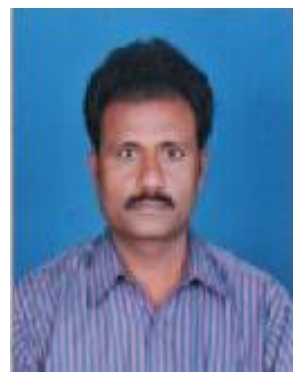

2. Mr. V.V.Rama Krishna completed his B.Tech. from JNTUHyderabad and M.Tech. from Godavari Institute of Technology \& Engineering, Rajahmundry. He has 3 years of Industrial and 5 years of teaching experience. Now he is working as Asst. Professor in Kakinada Institute of Technology \& Science, Divili and doing research in Thermal Engineering.

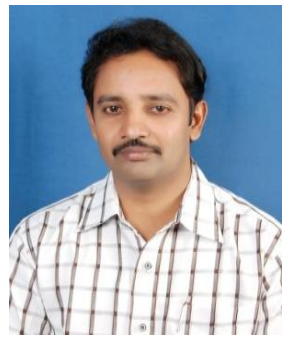

3.Mr. V.Subrahmanyam working as Assoc. Professor and Head of Mechanical Engineering Department in KITS-Divili Engineering college, Andhra Pradesh, India. He has 15 years of teaching experience in various reputed engineering colleges. He guided so many B.Tech and M.Tech projects. He has three publications in reputed international journals. He is doing research in NanoTechnology and Thermal Engineering. 